Disponível em:

http://editora.unoesc.edu.br/index.php/race

Race, Joaçaba, v. 15, n. 3, p. 871-890, set./dez. 2016

\title{
DESCENTRALIZAÇÃO DO IMPOSTO TERRITORIAL RURAL: UM ESTUDO APLICADO AOS MUNICÍPIOS DE MINAS GERAIS
}

Decentralization of the rural land tax: a study applied to the municipalities of Minas Gerais

Wellington de Oliveira Massardi

E-mail: wellingtonmassardi@hotmail.com

Mestre em Administração pela Universidade Federal de Viçosa; Graduado em Ciências Contábeis pela Faculdade Governador Ozanam Coelho. Professor da Faculdade

Governador Ozanam Coelho de Minas Gerais.

Rua Dr. Adjalme da Silva Botelho, 20, Seminário, 36500-000, Ubá, Minas Gerais, Brasil.

Patrícia Severino Araújo

E-mail: patriciaaraujo011@gmail.com Graduanda em Administração pela Faculdade Governador Ozanam Coelho.

João Paulo Ciribelli

E-mail: jpciri@hotmail.com

Doutor em Administração pela Universidade Nacional de Misiones (Argentina); Mestre em Gestão de Empresas pela Universidade de Évora (Portugal); Professor da

Faculdade Governador Ozanam Coelho.

Eraldo Teixeira da Silva

E-mail: eraldoteixeira@yahoo.com.br Mestre em Economia Doméstica pela Universidade Federal de Viçosa; Especialista em Gestão Sustentável de Florestas pela Ecobusiness School. Professor da Faculdade Governador Ozanam Coelho.

Artigo recebido em 29 de julho de 2015. Aceito em 25 de julho de 2016. 


\section{Resumo}

O Imposto Territorial Rural (ITR) é um tributo de competência da União, e 50\% de sua arrecadação deve ser transferido ao município de origem. Entretanto, existe a possibilidade de esse município apropriar-se de $100 \%$ da receita desde que assine um convênio com a Receita Federal e passe a ser o agente fiscalizador do tributo. Nesse sentido, na presente pesquisa tevese por objetivo analisar a arrecadação do ITR nos municípios de Minas Gerais nos anos 2011 e 2012, fazendo uma comparação entre os municípios conveniados e os que não são. Além disso, buscou-se identificar os impactos na arrecadação após o município aderir ao convênio. Metodologicamente foram utilizados os testes de Mann Whitney e o teste $\mathrm{T}$ de Student para amostras emparelhadas. Os resultados indicaram que, de maneira geral, os municípios conveniados possuem arrecadação superior aos municípios não conveniados. Entretanto, ao se analisar a arrecadação dos municípios antes e depois de aderirem ao convênio, ficou constatado que mesmo aumentando a média de arrecadação essa diferença não foi estatisticamente significativa, uma vez que se verificam alguns municípios que diminuíram a arrecadação do ITR após aderirem ao convênio.

Palavras-chave: Imposto Territorial Rural. Convênio. Arrecadação.

Abstract

The Rural Land Tax (ITR) is a tribute competence of the Union, and 50\% of its revenues must be transferred to the county of origin, however, there is a possibility of that municipality appropriate $100 \%$ of the revenue from signing an agreement with the Federal Revenue and becoming the supervisory agent of the tax. In this sense, in the present study one aimed to analyze the collection of the ITR in the municipalities of Minas Gerais in the years 2011 and 2012, making a comparison between the insured and the non-insured municipalities. In addition, it was sought to identify the impacts on the revenue after the municipality joining the agreement. Methodologically we used the Mann Whitney test and the Student t test for paired samples. The results indicated that, in general, the insured municipalities have higher revenues than the non-insured ones, however, when analyzing the collection of municipalities before and after joining the agreement, it was found that even increasing the average revenue this difference was not statistically significant, once there are some municipalities that decreased the collection of ITR after joining the agreement. Keywords: Rural Land Tax. Agreement. Collection.

\section{INTRODUÇÃO}

O federalismo fiscal brasileiro é marcado por disparidades inter-regionais antagônicas, fruto de um sistema de distribuição de competências tributárias que privile- 
giou os grandes centros urbanos, tornando-os mais modernos e dinâmicos, associado a mecanismos de repartição de receitas que desestimulam o esforço de arrecadação de municípios pequenos, os quais permanecem estagnados e atrasados em relação às metrópoles.

A baixa exploração da base tributária própria por parte desses municípios, bem como o alto nível de dependência das transferências intergovernamentais, mais especificamente do Fundo de Participação dos Municípios (FPM) e do Imposto sobre Circulação de Mercadorias e Serviços (ICMS), é um tema recorrente e pacífico na literatura. Entretanto, a necessidade de recursos para fornecimento de bens e serviços públicos à população local deve pautar a conduta do gestor municipal de maneira que promova uma melhor qualidade de vida aos munícipes.

Nesse sentido, destaca-se a potencialidade de ampliar a arrecadação municipal com recursos oriundos do Imposto Territorial Rural (ITR), que é um tributo de competência da União, conforme disposto no inciso VI do Art. 153 da Constituição Federal; 50\% do valor arrecadado deve ser transferido ao município de origem do imóvel (BRASIL, 1988).

Contudo, no $\S 4^{\circ}$, inciso III, do referido artigo, que foi alterado pela Emenda Constitucional n. 42/03, é estabelecida a previsão para que os municípios possam optar pela fiscalização do tributo, desde que não implique redução do imposto ou qualquer outra forma de renúncia fiscal. Nessa situação, o município passa a apropriar 100\% do valor arrecadado (BRASIL, 2003).

Com o objetivo de regulamentar o inciso III do § 4o do Art. 153 da Constituição Federal, foi publicada a Lei n. 11.250/05, que prevê a possibilidade de celebração de convênios entre a União, por intermédio da Secretaria da Receita Federal (SRF), e os Municípios que assim optarem, visando a delegar as atribuições de fiscalização, inclusive à de lançamento dos créditos tributários, e de cobrança do ITR, por isso, cabendo a totalidade da arrecadação (BRASIL, 2005).

No entanto, a arrecadação histórica do ITR é ínfima, principalmente quando comparada a outros países. Em países como Estados Unidos e Canadá, o imposto cobrado sobre as terras rurais representa $5 \%$ da receita tributária total, enquanto na França e na Itália esse percentual é de 3\%. Em países da América do Sul, como Uruguai e Chile, esses percentuais são, respectivamente, 6\% e 4\%, enquanto no Brasil, em nenhuma vez, nas últimas décadas, foi alcançado 0,3\%, mesmo sendo um país com grandes dimensões territoriais e predominantemente rural (SOUZA, 2004).

Ao analisar regionalmente a distribuição desse tributo, Oliveira (2010) identificou que o Estado de São Paulo é o que mais arrecada ITR, embora sua extensão 
territorial seja apenas 2,9\% do território nacional. Em segundo lugar está o Estado de Minas Gerais, que é o quarto maior Estado do País, e mesmo assim possui uma arrecadação do ITR 67\% menor que do Estado de São Paulo.

Atualmente, o Estado de Minas Gerais possui 248 municípios conveniados à Secretaria da Receita Federal, e por isso são responsáveis pela fiscalização e administração do ITR incidente sobre os imóveis localizados em suas dimensões territoriais, consequentemente, apropriam 100\% das receitas provenientes dessa arrecadação.

Considerando os aspectos introdutórios, foram elaborados os seguintes questionamentos: os municípios conveniados possuem arrecadação do ITR superior aos municípios não conveniados? Houve aumento de arrecadação após aderirem à descentralização da cobrança?

Dessa forma, na presente pesquisa teve-se por objetivo analisar a arrecadação do Imposto Territorial Rural por parte dos municípios de Minas Gerais, fazendo uma distinção entre os municípios conveniados e não conveniados, para verificar se há diferença entre os grupos no que se refere à arrecadação do ITR e se houve aumento da arrecadação após a adesão ao convênio.

\section{REFERENCIAL TEÓRICO}

\subsection{IMPOSTO TERRITORIAL RURAL}

No ano 1843, na fase inicial da Lei de Terras, houve uma tentativa de instituição do ITR, o que gerou grande insatisfação e repugnação por parte dos latifundiários em relação à cobrança desse imposto. O governo brasileiro, diante de forte pressão exercida por parte dos fazendeiros, cedeu e renunciou à cobrança do imposto (OLIVEIRA, 2010).

De acordo com Souza (2004), a instituição do imposto territorial ocorreu pela primeira vez no Brasil somente no ano 1891 por meio da Constituição Republicana; nessa Constituição o imposto era de competência dos estados membros. Essa situação permaneceu nas constituições seguintes, até a Constituição de 1961, na qual passou a ser um tributo de competência municipal por meio da Emenda Constitucional n. 5.

O ITR, até o ano 1961 sob competência do Estado, foi marcado por uma série de fatores que o tornou ineficaz como gerador de receita para o Estado. $O$ fato de não haver uma fiscalização eficiente e haver uma cobrança com alíquotas inconstantes, além da falta de uma base confiável de dados cadastrais para sua cobrança, fez do ITR nesse período um tributo distante de seus objetivos principais de cunho administrativo, social e econômico (SOUZA; JORGE, 1999; WILLIAMSON, 2008). 
Três anos se passaram e, em 1964, a responsabilidade de arrecadar e administrar o ITR passou para a competência da União, sendo atribuídas funções extrafiscais a esse tributo. Foi nesse momento que o Governo brasileiro deixou transparecer pela primeira vez sinais concretos de que o ITR auxiliaria as políticas públicas de descentralização e melhor distribuição de terras mediante uma reforma agrária, decretando-se, assim, o Estatuto da Terra com a edição da Lei n. 4.504, em 30 de novembro de 1964 (SOUZA, 2004).

Em relação à criação desse estatuto, Bergold (2012, p. 88) explica que:

O Estatuto da Terra estabeleceu o conceito de reforma agrária, como política voltada à alteração da estrutura fundiária, bem como a modificação da relação entre o homem, a propriedade e o uso da terra, com a finalidade de atender ao princípio de justiça social e promover o desenvolvimento do país. A reforma agrária foi integrada com a Política Agrícola, também definida pela lei, visando amparar a propriedade rural, orientando as atividades agropecuárias para o desenvolvimento da economia, assegurando o pleno emprego e harmonizando-as com o processo de industrialização nacional.

Atualmente, o ITR está previsto no artigo n. 153 da Constituição Federal de 1988 como um tributo de competência da União, sendo 50\% de sua arrecadação transferido aos municípios de origem. Entretanto, existe a possibilidade de o município receber $100 \%$ do valor por meio de convênio com a SRF, cabendo-lhe as funções de arrecadação e fiscalização desse imposto (MACHADO, 2010).

\subsection{A REGULAMENTAÇÃO PELA LEI N. 9.393/96}

Até o ano 1990, o Instituto Nacional de Colonização e Reforma Agrária (INCRA) era o órgão a quem competia as funções de arrecadação, fiscalização e tributação das terras e do ITR. Mas com a criação da Lei n. 8.022/90 tais atribuições passaram para a responsabilidade da Secretaria da Receita Federal. Entretanto, há uma intensificação nas discussões sobre a descentralização do tributo e sua importância para a composição das receitas públicas (OLIVEIRA, 2010; INTERNATIONAL MONETARY FUND, 1992).

Em 1996, por meio da Lei n. 9.393 surge a possibilidade da criação de convênios entre a SRF, as Secretarias Estaduais de Agricultura, o INCRA, a Fundação Nacional do Índio (Funai) e o Instituto Brasileiro do Meio Ambiente e dos Recursos 
Naturais Renováveis (Ibama), com o intuito de ajudar na fiscalização das informações passadas pelos contribuintes que comporão o Declaração do Imposto sobre a Propriedade Territorial Rural (DITR) (SOUZA, 2004).

De acordo com Machado (2010), a Lei n. 9.393 estabelece que o ITR é um tributo cujo período de apuração deve ser anual, feito no dia $1^{\circ}$ de janeiro de cada ano. O Art. $1^{\circ}$ do referido diploma legal estipula que o fator gerador do ITR é a propriedade, o domínio útil ou a posse de imóvel por natureza, localizado fora do perímetro urbano do município.

Entretanto, deve-se observar que os proprietários que tiverem a posse de propriedades que são denominadas pequenas glebas estão imunes quanto ao pagamento do ITR, conforme descrito no Art. $2^{\circ}$ da Lei n. 9.393/96:

Art. $2^{\circ}$ Nos termos do art. 153, $\S 4^{\circ}$, in fine, da Constituição, o imposto não incide sobre pequenas glebas rurais, quando as explore, só ou com sua família, o proprietário que não possua outro imóvel. Parágrafo único. Para os efeitos deste artigo, pequenas glebas rurais são os imóveis com área igual ou inferior a: I - 100 ha, se localizado em município compreendido na Amazônia Ocidental ou no Pantanal mato-grossense e sul-mato-grossense;

II - 50 ha, se localizado em município compreendido no Polígono das Secas ou na Amazônia Oriental;

III - 30 ha, se localizado em qualquer outro município. (BRASIL, 1996).

A apuração e o pagamento do ITR são feitos pelo próprio contribuinte. Entretanto, para apuração do imposto, deve-se considerar alguns conceitos que estão descritos no Art. 10 da Lei n. 9.393/96 e que estão sintetizados no Quadro 1.

Quadro 1 - Conceitos para apuração do ITR

\begin{tabular}{|l|l|}
\hline \multicolumn{1}{|c|}{ Conceito } & \multicolumn{1}{c|}{ Descrição } \\
\hline $\begin{array}{l}\text { Valor da } \\
\text { Terra Nua } \\
\text { (VTN) }\end{array}$ & $\begin{array}{l}\text { Corresponde ao valor do imóvel, sendo excluídos os valores relativos a construções, } \\
\text { instalações e benfeitorias; culturas permanentes e temporárias; pastagens cultivadas e } \\
\text { melhoradas; florestas plantadas. }\end{array}$ \\
\hline & $\begin{array}{l}\text { Representa a área total do imóvel, menos as áreas de preservação permanente e de re- } \\
\text { Área tribu- } \\
\text { tável }\end{array}$ \\
& $\begin{array}{l}\text { imprestáveis para qualquer tipo de exploração; sob regime de servidão ambiental; co- } \\
\text { bertas por florestas nativas; alagadas para fins de constituição de reservatório de usinas } \\
\text { hidrelétricas autorizada pelo poder público. }\end{array}$ \\
\hline
\end{tabular}




\begin{tabular}{|l|l|}
\hline $\begin{array}{l}\text { Valor da } \\
\text { Terra Nua } \\
\text { tributável } \\
\text { (VTNt) }\end{array}$ & Obtido pela multiplicação do VTN pelo quociente entre a área tributável e a área total. \\
\hline $\begin{array}{l}\text { Área apro- } \\
\text { veitável }\end{array}$ & $\begin{array}{l}\text { Refere-se à área que for passível de exploração agrícola, pecuária, granjeira, aquícola ou } \\
\text { florestal, excluídas as áreas ocupadas por benfeitorias úteis e necessárias; e de que tratam } \\
\text { a área tributável. }\end{array}$ \\
\hline $\begin{array}{l}\text { Área efe- } \\
\text { tivamente } \\
\text { utilizada }\end{array}$ & $\begin{array}{l}\text { Constitui na porção do imóvel que no ano anterior tenha sido plantada com produtos ve- } \\
\text { de atividades granjeira e aquícola; sido objeto de implantação de projeto técnico. }\end{array}$ \\
\hline $\begin{array}{l}\text { Grau de } \\
\text { Utilização } \\
\text { (GU) }\end{array}$ & É a relação percentual entre a área efetivamente utilizada e a área aproveitável. \\
\hline
\end{tabular}

Fonte: elaborado a partir de Brasil (1996).

De acordo com o Art. 11 da Lei n. 9.393/96, o valor do imposto será apurado aplicando-se sobre o Valor da Terra Nua Tributável (VTNt) a alíquota correspondente prevista no Anexo da Lei e apresentada na Tabela 1, que consideram a área total do imóvel e o Grau de Utilização (GU).

O Grau de Utilização tem como objetivo penalizar e desestimular a manutenção de propriedades não produtivas. Suas alíquotas são progressivas e variam de 0,03\% a 20\%, em que a propriedades com até 50 hectares, com um GU maior que 80\%, a alíquota cobrada é de 0,03\%; já a propriedades acima de 5.000 hectares, com um GU de até 30\%, a alíquota a ser cobrada chega até 20\% (LUZ; CRUZ; UHLMANN, 2012).

Tabela 1 - Alíquotas para tributação do imposto territorial rural

\begin{tabular}{lrrrrr}
\hline \multicolumn{1}{c}{$\begin{array}{c}\text { Área Total do Imóvel } \\
\text { (em hectares) }\end{array}$} & $\begin{array}{c}\text { Maior } \\
\text { que } \mathbf{8 0}\end{array}$ & $\begin{array}{c}\text { Maior que } \\
\mathbf{6 5} \text { até } \mathbf{8 0}\end{array}$ & $\begin{array}{c}\text { Maior que } \\
\mathbf{5 0} \text { até } \mathbf{6 5}\end{array}$ & $\begin{array}{c}\text { Maior que } \\
\mathbf{3 0} \text { até } \mathbf{5 0}\end{array}$ & $\begin{array}{c}\text { Até } \\
\mathbf{3 0}\end{array}$ \\
\hline Até 50 & 0,03 & 0,20 & 0,40 & 0,70 & 1,00 \\
Maior que 50 até 200 & 0,07 & 0,40 & 0,80 & 1,40 & 2,00 \\
Maior que 200 até 500 & 0,10 & 0,60 & 1,30 & 2,30 & 3,30 \\
Maior que 500 até 1.000 & 0,15 & 0,85 & 1,90 & 3,30 & 4,70 \\
Maior que 1.000 até 5.000 & 0,30 & 1,60 & 3,40 & 6,00 & 8,60 \\
Acima de 5.000 & 0,45 & 3,00 & 6,40 & 12,00 & 20,00 \\
\hline
\end{tabular}

Fonte: Brasil (1996). 
A base de cálculo para apuração do ITR constitui o Valor da Terra Nua tributável, que é uma grandeza que permanece constante e não sofre alteração em decorrência do grau de utilização. Dessa forma, quanto maior for o grau de utilização da terra, menor será o valor a ser pago do tributo, ou seja, quem produz mais paga menos imposto do que aquele que mantém a propriedade improdutiva (RODRIGUES, 2012).

\subsection{ESTABELECIMENTO DE CONVÊNIOS ENTRE SRF E MUNICÍPIOS}

Araújo et al. (2014) fazem referência a vários autores que relatam que o motivo de o ITR ser um tributo ainda insignificante quanto a sua arrecadação é em virtude de ser autodeclaratório e de ainda não haver uma fiscalização eficiente, pois a atual responsável por sua fiscalização, a Receita Federal, não possui em seu quadro de pessoal um número suficiente de profissionais capacitados para uma melhor fiscalização.

Desde sua criação o Imposto Territorial Rural não atingiu índices significativos na receita de sua arrecadação, sendo um dos motivos de desestímulo dos governos locais quanto à colaboração na fiscalização desse imposto. Já no cenário federal, em virtude das dificuldades de controle e fiscalização do ITR enfrentadas, desde por volta da década de 1990, quando ocorreu o início da discussão sobre mudanças na competência desse tributo, buscou-se meios para descentralizar sua cobrança (BOTELHO; BRITTO; SOUZA, 2011).

Mas tal cenário nacional viria a ter uma oportunidade de mudança com a criação da Lei n. 11.250, em dezembro de 2005. Mediante convênio com a União, com o intermédio da Secretaria da Receita Federal, os municípios ficariam responsáveis pela fiscalização, lançamento e arrecadação do ITR, e como recompensa, ao invés de ficarem com 50\% de sua arrecadação conforme disposto em lei, passariam a ficar com 100\%, desde que não ocorresse nenhuma omissão das informações repassadas, redução do imposto ou qualquer outra forma de renúncia fiscal (LUZ; CRUZ; UHLMANN, 2012).

E, para a celebração do convênio, em 2008, foi criado o Comitê Gestor do Imposto sobre a Propriedade Territorial Rural (CGITR), por meio do Decreto n. 6.433, no qual estão dispostas todas as funções atribuídas à administração do ITR, e estas são delegadas sob forma de opção aos municípios que aderirem ao convênio (BRASIL, 2008).

De acordo com o Art. 10 do referido diploma legal, essa delegação está condicionada à protocolização, sendo que o município e o Distrito Federal sob termo de opção terão que cumprir requisitos e condições necessários para aderirem ao convênio, dispostos no CGITR, conforme estabelecidos pela SRF (BRASIL, 2008). 
Em relação ao termo de opção, tudo será feito por meio eletrônico, o município optante, por meio de uma assinatura eletrônica, terá acesso a um certificado digital válido disponível no portal do ITR (BRASIL, 2008).

Mas, antes de aderirem ao convênio, os municípios teriam que cumprir várias condições e especificações para que fosse validado, e, para isso, foi criada a Instituição Normativa RFB n. 884, segundo a qualteriam que:

- Dispor de estrutura de tecnologia da informação suficiente para acessar os sistemas da RFB, que contemple equipamentos e redes de comunicação;

- Possuir quadro de carreira de servidores com atribuição de lançamento de créditos tributários;

- Arcar com os custos de treinamento a seus servidores e com expedição de auto de infração, intimação, avisos e outros documentos. (BRASIL, 2008)

Apesar de todos os requisitos necessários que os municípios têm que cumprir para que ocorra a celebração do convênio, há a possibilidade de uma arrecadação e fiscalização mais eficiente do ITR, em razão da proximidade entre os agentes arrecadadores e os contribuintes, podendo ter, assim, uma base de dados mais confiável retratando o mais próximo da realidade das propriedades rurais, aumentando a potencialidade de sua arrecadação. Além disso, os municípios que após aderirem ao convênio aumentassem sua receita, como resultado, poderiam oferecer bens e serviços para sua população, bem como suprir as necessidades do município como um todo, sendo, assim, um possível recurso de grande ajuda principalmente para os municípios pouco desenvolvidos.

\section{METODOLOGIA}

\subsection{CARACTERIZAÇÃO DA PESQUISA}

O presente estudo trata-se de uma pesquisa descritiva de caráter predominantemente quantitativo com a qual se tem o objetivo de analisar a arrecadação do ITR por parte dos municípios mineiros, fazendo uma comparação entre os municípios que aderiram ao convênio com SRF e, por isso, são denominados Conveniados, e os municípios que não são adeptos à descentralização da arrecadação do ITR, denominados Não Conveniados. 
Essa comparação foi realizada para 2011 e 2012 por serem os anos com informações mais recentes no banco de dados Finanças do Brasil (Finbra). A amostra compreende 801 municípios que tinham informações disponíveis; desses municípios, apenas 201 eram conveniados em 2011. No ano 2012, o número de municípios conveniados passou para 213, ou seja, houve um aumento de 12 municípios.

Dessa forma, também foi analisado o desempenho da arrecadação do ITR dos municípios que não eram conveniados em 2011 e passaram a ser em 2012 para verificar se houve aumento significativo na arrecadação desses municípios após a adesão ao processo de descentralização da arrecadação do ITR.

Considerando os objetivos com a pesquisa, foram criadas as hipóteses demonstradas no Quadro 1:

Quadro 1 - Hipóteses a serem testadas

\begin{tabular}{|c|c|c|c|}
\hline $\mathbf{N}^{0}$ & Formulação & Hipótese Nula & Hipótese Alternativa \\
\hline 1 & $\begin{array}{l}\text { Os municípios Conveniados possuem uma média de } \\
\text { arrecadação do ITR, em 2011, superior aos municípios } \\
\text { NÃO CONVENIADOS. }\end{array}$ & & \\
\hline 2 & $\begin{array}{l}\text { Os municípios Conveniados possuem uma média de } \\
\text { arrecadação do ITR, em 2012, superior aos municípios } \\
\text { NÃO CONVENIADOS. }\end{array}$ & & \\
\hline 3 & $\begin{array}{l}\text { Os municípios Não conveniados em } 2011 \text { aumentaram a } \\
\text { arrecadação do ITR após aderirem ao processo de des- } \\
\text { centralização da cobrança em } 2012 \text {. }\end{array}$ & & \\
\hline
\end{tabular}

Fonte: os autores

Para testar as hipóteses 1 e 2, foi utilizado o teste Mann-Whitney, que é um teste não paramétrico usado para comparar as funções de distribuição de uma variável medida em duas amostras independentes. Esse teste é utilizado como uma forma alternativa ao teste t de Student para amostras independentes quando os pressupostos da normalidade não são atendidos, visto que a hipótese de normalidade da distribuição foi rejeitada por meio do teste Komogorov-Sminorv considerando um nível de significância de 5\%.

Em relação à hipótese 3, foi utilizado o teste de média para amostras emparelhadas, uma vez que foi atendido o pressuposto da normalidade. De acordo com Bussab e Morettin (1987, p. 283), o teste de amostra emparelhada “[...] é usado quando as observações de duas amostras são feitos do mesmo indivíduo, medindo suas características antes e depois dele ser submetido a um tratamento.” 


\section{RESULTADOS E DISCUSSÕES}

Com o intuito de facilitar a visualização da disposição geográfica dos municípios Conveniados e Não conveniados do Estado de Minas Gerais no período de 2011 e 2012, foi elaborado o Mapa 1, no qual se pode observar que, dos 588 municípios Não conveniados pesquisados nesse estudo, boa parte está concentrada no Norte de Minas, passando pelo Vale do Jequitinhonha, Rio Doce, Zona da Mata, Centro-Oeste, indo até o Sul de Minas Gerais.

Em relação aos municípios Conveniados em 2011 e 2012, dos 213 municípios verifica-se que há maior concentração no Triângulo Mineiro, no Alto Paranaíba e no Noroeste de Minas onde há municípios com maior extensão territorial e, consequentemente, existe maior possibilidade de arrecadação do ITR.

\section{Mapa 1 - Representação geográfica dos municípios conveniados e não conveniados}

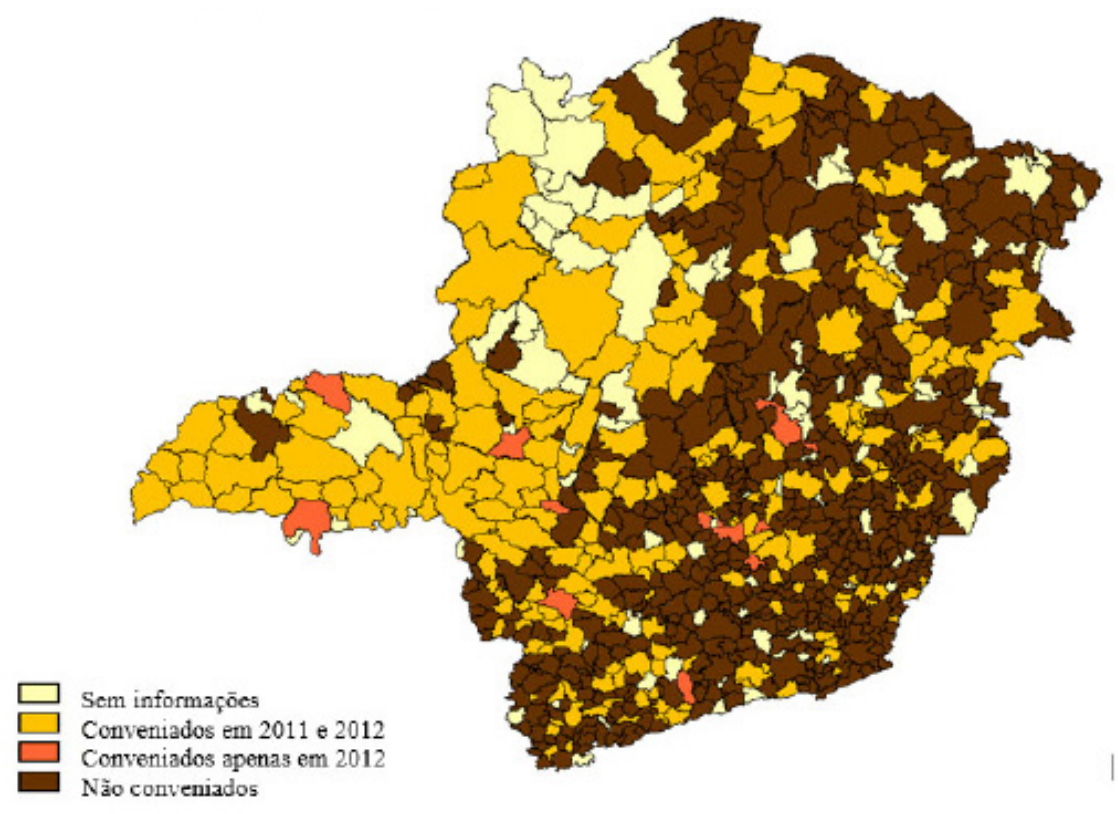

Fonte: os autores.

Posteriormente, foi realizada uma análise das estatísticas descritivas da arrecadação do ITR em 2011 e 2012, separando os municípios em conveniados e não conveniados, conforme demonstrado na Tabela 2. 
Verificou-se que a média de arrecadação, tanto em 2011 quanto em 2012, dos municípios conveniados, é superior à média de arrecadação dos municípios não conveniados. Entretanto, deve-se destacar que mesmo não sendo conveniados, existem municípios que possuem elevada arrecadação do ITR, como é o caso do Município de Santa Barbara em 2011 (R\$ 1.144.257,00) e de Uberlândia em 2012 (R\$ 1.017.251,00).

Outro ponto que merece ser destacado é que em ambos os grupos existem municípios que não possuem arrecadação do ITR, seja em 2011, seja em 2012, sendo constatados 13 municípios nessa situação, dos quais três são conveniados. Entre esses municípios, quatro não possuem arrecadação em ambos os anos, Ladainha, Jampruca, São Félix de Minas e São José da Safira, e apenas o primeiro é conveniado.

Tabela 2 - Estatísticas descritivas da arrecadação do ITR em 2011 e 2012

\begin{tabular}{lcccccccc}
\hline $\begin{array}{c}\text { Mu- } \\
\text { nicí- } \\
\text { pios }\end{array}$ & Ano & N & Mínimo & Máximo & Média & $\begin{array}{c}\text { Desvio pa- } \\
\text { drão }\end{array}$ & $\begin{array}{c}\text { Assime- } \\
\text { tria }\end{array}$ & Curtose \\
\hline $\begin{array}{l}\text { Con- } \\
\text { venia- }\end{array}$ & 2011 & 201 & 0,00 & $3.906 .538,62$ & $216.253,20$ & $456.374,18$ & 4,685 & 28,532 \\
$\begin{array}{l}\text { dos } \\
\text { Não }\end{array}$ & 2012 & 213 & 0,00 & $3.497 .263,54$ & $268.359,18$ & $532.991,78$ & 3,394 & 13,856 \\
$\begin{array}{l}\text { Con- } \\
\text { venia- } \\
\text { dos }\end{array}$ & 2012 & 500 & 0,00 & $1.144 .257,00$ & $30.514,90$ & $96.541,49$ & 8,039 & 73,935 \\
\hline
\end{tabular}

Fonte: os autores.

O coeficiente de curtose positivo indica que a curva no histograma de distribuição de frequência apresenta forma de um pico. Em relação à assimetria, verifica-se um coeficiente positivo, o que caracteriza uma distribuição assimétrica à direita, ou seja, a média é superior à mediana em razão da existência de municípios com elevada arrecadação do ITR, como é o caso do município de Uberaba, que obteve uma arrecadação de R\$ 3.906.538,62 em 2011.

Segundo Hair Júnior et al. (2005), uma distribuição deve ser considerada substancialmente assimétrica se o coeficiente de assimetria for superior a +1 ou inferior a -1. Para que a curva seja considerada muito aguda, o coeficiente de curtose deve ser superior a 3; nesse sentido, constata-se que tanto o coeficiente de assimetria quanto o de curtose ultrapassam os limites sugeridos por esses autores.

Em virtude disso, foi realizado o teste Kolmogorov-Smirnov para verificar a normalidade da distribuição, uma vez que é pressuposto necessário para realização do teste de médias para amostras independentes. Os resultados destes estão apresentados 
na Tabela 3 e indicam que se deve rejeitar a hipótese nula em nível de 1\%, ou seja, não há normalidade na arrecadação do ITR nos anos 2011 e 2012.

\begin{tabular}{cccc}
\multicolumn{4}{c}{ Tabela 3 - Teste de normalidade para amostra independente } \\
\hline Variável & Estatística & df & Sig. \\
\hline Arrecadação ITR 2011 & 0,382 & 801 & 0,000 \\
Arrecadação ITR 2012 & 0,384 & 801 & 0,000 \\
\hline
\end{tabular}

Fonte: os autores.

Para fazer uma comparação entre a arrecadação do ITR dos municípios conveniados e não conveniados foi realizado o teste de Maan-Whitney, que é uma alternativa para o teste de média para amostras independentes quando a normalidade dos dados não é obtida. O teste de Maan-Whitney é amplamente utilizado em trabalhos na área das Ciências Sociais Aplicadas.

Os resultados do teste de Mann-Whitey estão apresentados na Tabela 4; para ambas as hipóteses formuladas o p-valor foi de 0,000, logo, deve-se rejeitar a hipótese nula de que a arrecadação entre os grupos é a mesma e confirma-se que os municípios Conveniados possuem arrecadação superior aos demais tanto em 2011 quanto em 2012.

Tabela 4 - Resultado do teste de Mann-Whitney

\begin{tabular}{llcl}
\hline \multicolumn{1}{c}{ Formulação } & \multicolumn{1}{c}{$\begin{array}{c}\text { Hipótese } \\
\text { Nula }\end{array}$} & Sig. & Decisão \\
\hline $1 \quad \begin{array}{l}\text { Os municípios Conveniados possuem uma média } \\
\text { de arrecadação do ITR, em 2011, superior aos } \\
\text { municípios Não conveniados. }\end{array}$ & 0,000 & $\begin{array}{l}\text { Rejeitar a hipótese } \\
\text { nula }\end{array}$ \\
& $\begin{array}{l}\text { Os municípios Conveniados possuem uma média } \\
\text { de arrecadação do ITR, em 2012, superior aos } \\
\text { municípios Não conveniados. }\end{array}$ & 0,000 & $\begin{array}{l}\text { Rejeitar a hipótese } \\
\text { nula }\end{array}$ \\
\hline
\end{tabular}

Fonte: os autores.

Em seguida, foi realizado o teste $\mathrm{T}$ de Student para amostras emparelhadas com o objetivo de verificar a arrecadação dos municípios após aderirem ao convênio. Primeiramente, foram identificados os municípios que não eram conveniados em 2011 e passaram a ser em 2012; a amostra apresentava 12 municípios na referida situação.

Na Tabela 5 são apresentadas as estatísticas descritivas da arrecadação do ITR por parte desses municípios, antes e depois de aderirem ao convênio com a Receita Federal. Verifica-se que houve aumento na média de arrecadação, que passou de 
R\$ 294.528,94 em 2011 para R\$ 671.314,27 em 2012, o que representa um aumento de $127,93 \%$.

Em ambos os anos esses valores foram superiores à média geral de todos os municípios conveniados, uma vez que os municípios que compõem a amostra já possuíam alta arrecadação do ITR antes de serem conveniados, e após assinarem o convênio houve um aumento na média de arrecadação, com destaque para o Município de Frutal, que apresentou a menor arrecadação em $2011(0,00)$ e a maior no ano seguinte (R\$2.086.080,47).

Tabela 5 - Estatísticas descritivas para amostra emparelhada

\begin{tabular}{rrrrrrr}
\hline & \multicolumn{1}{c}{ Mínimo } & \multicolumn{1}{c}{ Máximo } & \multicolumn{1}{c}{ Média } & Desvio padrão & Assimetria & Curtose \\
\hline ANTES & 0,00 & $958.734,05$ & $294.528,94$ & $353.152,20$ & 1,11 & $-0,29$ \\
\hline DEPOIS & $13.546,21$ & $2.086 .080,47$ & $671.314,27$ & $753.491,61$ & 0,96 & $-0,67$ \\
\hline
\end{tabular}

Fonte: os autores.

Os coeficientes de assimetria e curtose indicam que a arrecadação do ITR por parte desses municípios apresentam características de normalidade, pois apresentaram baixo coeficiente de assimetria e curtose; ambos foram inferiores aos limites sugeridos por Hair Júnior et al. (2005), o que indica a provável distribuição normal dos dados.

Para constatar a normalidade da distribuição, foi realizado o teste Kolmogorov-Smirnov sendo rejeitada a hipótese nula a 1\%, ou seja, deve-se assumir que os dados apresentam uma distribuição normal; assim, para fazer comparação da arrecadação do ITR antes e depois da adesão ao convênio, utilizou-se o teste de médias paramétrico para amostras emparelhadas. Os resultados do teste de normalidade estão apresentados na Tabela 6.

\begin{tabular}{cccc} 
Tabela 6 - Teste de normalidade para amostra emparelhada \\
\hline Variável & Estatística & df & Sig. \\
\hline Arrecadação ITR 2011 & 0,235 & 12 & 0,065 \\
\hline Arrecadação IRT 2012 & 0,264 & 12 & 0,021 \\
\hline
\end{tabular}

Fonte: os autores.

Após verificar a normalidade da distribuição que é pressuposto para a realização do teste paramétrico, foi realizado o teste T de Student para amostras emparelhadas a fim de verificar se os municípios melhoraram a arrecadação do ITR após aderirem ao convênio com a Receita Federal. 
Os resultados do teste estão apresentados na Tabela 7, na qual se pode verificar que não é possível rejeitar a hipótese nula do teste em nível de significância de 1\%, pois o p-valor foi igual a 0,07, dessa forma, deve-se rejeitar a hipótese alternativa de que os municípios Não conveniados em 2011 aumentaram a arrecadação do ITR após aderirem ao processo de descentralização da cobrança em 2012.

Tabela 7 - Teste de médias para amostras emparelhadas

\begin{tabular}{ccccccccc}
\hline & \multicolumn{9}{c}{ 95\% Intervalo de confiança da diferença } & & & \\
\cline { 2 - 6 } Par 1 & Média & $\begin{array}{c}\text { Desvio } \\
\text { padrão }\end{array}$ & $\begin{array}{c}\text { Erro } \\
\text { padrão da } \\
\text { média }\end{array}$ & Inferior & Superior & t & df & Sig. \\
\hline ITR 2011 & $-376.785,34$ & $639.156,36$ & $184.508,55$ & $-782.885,91$ & $29.315,24$ & $-2,04$ & 11,00 & 0,07 \\
IRT 2012 & & & & & & & &
\end{tabular}

Fonte: os autores.

Os testes indicaram que não houve um aumento significativo na arrecadação do ITR para esses municípios após aderirem à descentralização da cobrança, ou seja, mesmo assumindo $100 \%$ da arrecadação do ITR, a arrecadação era maior quando administrada pela Receita Federal.

Esse resultado sugere que os municípios diminuíram a arrecadação do ITR após assinarem o convênio. Na amostra analisada constataram-se três municípios nessa situação, conforme apresentado na Tabela 8. Esses municípios tiveram uma redução média da arrecadação correspondente a 17,41\%, que vai de encontro ao determinado pela legislação, uma vez que a descentralização do ITR não pode implicar renúncia fiscal, ou seja, não pode haver redução da arrecadação do tributo, conforme o $\S 2^{\circ}$ do Art. $1^{\circ}$ da Lei n. $11.250 / 05$.

Tabela 8 - Municípios que diminuíram a arrecadação do ITR

\begin{tabular}{lccc}
\hline Município & \multicolumn{1}{c}{$\mathbf{2 0 1 1}$} & $\mathbf{2 0 1 2}$ & \multicolumn{1}{c}{$\boldsymbol{\Delta} \%$} \\
\hline Aiuruoca & $14.723,48$ & $13.546,21$ & $-8,00 \%$ \\
Brumadinho & $309.759,82$ & $267.552,31$ & $-13,63 \%$ \\
Congonhas & $691.848,29$ & $480.152,19$ & $-30,60 \%$ \\
\hline
\end{tabular}

Fonte: os autores.

Esses resultados chamam a atenção para alguns aspectos que devem ser considerados no processo de descentralização da cobrança do ITR que estão relacionados aos custos financeiros, e outro aspecto refere-se a fatores políticos que moldam a postura dos contribuintes e dos governantes. 
De acordo com a Instrução Normativa RFB n. 884/08, para a celebração do convênio, os municípios devem dispor de uma estrutura tecnológica que possibilite o acesso aos sistemas da RFB, além disso há necessidade de qualificação técnica de funcionários que passarão a assumir as responsabilidade de lançamento de créditos tributários e demais atribuições de fiscalização.

A necessidade de um quadro de profissionais técnicos devidamente qualificados enseja em aumento de custos com investimento em treinamentos, tecnologias, equipamentos de informática, softwares e aumento no número de agentes de fiscalização. Dessa forma, deve ser feita uma análise de viabilidade econômica e financeira, pois o aumento da arrecadação do ITR pode ser inferior ao aumento dos custos necessários à celebração do convênio.

Outro fator que deve ser considerado é o aspecto político que influencia o comportamento dos contribuintes e dos governantes. Em relação aos governantes, estes podem não ter interesse em aumentar a pressão tributária sobre seus eleitores, pois causará uma insatisfação generalizada que prejudicará uma possível reeleição ou a eleição de seu sucessor. Quanto aos contribuintes, estes podem ter o comportamento de não se preocupar com a obrigação tributária com o município em virtude da proximidade com o prefeito e uma possível intervenção. Isso tem relação com aspectos psicológicos subjetivos do contribuinte, pois uma coisa é dever ao Governo Federal, e outra, ao prefeito local.

\section{CONSIDERAÇÕES FINAIS}

A necessidade de recursos para promover melhorias para a população local faz com que os municípios busquem sempre fontes alternativas de financiamento de bens e serviços públicos. Entretanto, a grande maioria dos municípios dependem, principalmente, das transferências intergovernamentais para sobrevivência e acabam não se esforçando para conquistar a independência fiscal.

Nesse cenário caótico, que levanta discussões acerca das atuais regras do federalismo fiscal brasileiro, tanto no que se refere às competências tributárias quanto aos mecanismos de transferências entre as instâncias de governo, a descentralização do ITR acaba sendo uma ferramenta que tenta minimizar os efeitos distorcivos do atual sistema federalista.

Entretanto, o processo de descentralização do ITR implica alguns aspectos que devem ser considerados, pois impactam consideravelmente a arrecadação do tributo. Um desses aspectos refere-se ao custo-benefício da descentralização, uma vez que ao assumir a totalidade de arrecadação do ITR, o município também passa a assu- 
mir as responsabilidades de cobrança e fiscalização, o que implica aumento de custos, dessa maneira, o acréscimo da arrecadação pode não ser significativo.

Na presente pesquisa constatou-se que, de maneira geral, os municípios conveniados possuem uma arrecadação do ITR superior aos municípios que não aderiram ao processo de descentralização da cobrança, tanto em 2011 quanto em 2012, o que confirma as hipóteses iniciais deste trabalho.

Entretanto, ao verificar o grupo de municípios que não eram conveniados em 2011 e passaram a ser em 2012, constatou-se que mesmo aumentando a média de arrecadação esse aumento não foi significativo em decorrência dos municípios que ao invés de aumentarem a arrecadação após aderirem ao convênio reduziram o valor arrecadado, rejeitando a hipótese inicial de que os municípios aumentaram a arrecadação após aderirem ao processo de descentralização da cobrança.

Diante de tais constatações, destacam-se as limitações da pesquisa, que estão relacionadas ao método utilizado. Assim, para pesquisas futuras, sugere-se a utilização de metodologias mais inferenciais que busquem identificar os fatores que impactam a arrecadação desse tributo, como o tamanho do município, o grau de urbanização e o valor adicionado pelo setor agropecuário.

\section{REFERÊNCIAS}

ARAÚJO, A. L. et al. Vulnerabilidade do sistema declaratório para tributação da propriedade rural. In: SIMPÓSIO BRASILEIRO DE CIÊNCIAS GEODÉSICAS E TECNOLOGIAS DA GEOINFORMAÇÃO, 5., 2014, Recife. Anais... Recife, 2014.

BERGOLD, R. C. A reforma agrária capitalista brasileira. Revista Paradigma, Ribeirão Preto, ano 17, n. 21, p. 76-96, jan./dez. 2012.

BOTELHO, A. P.; BRITTO, M.; SOUZA, J. G. O perfil de arrecadação do Imposto Territorial Rural nos municípios do EDR de Jaboticabal- SP. Revista de Geografia Agrária, v. 6, n. 12, p. 224-245, ago. 2011.

BRASIL. Constituição. República Federativa do Brasil de 1988. Brasília, DF: Senado Federal, 1988.

BRASIL. Decreto n. 6.433, de 15 de abril de 2008. Institui o Comitê Gestor do Imposto sobre a Propriedade Territorial Rural - CGITR e dispõe sobre a forma de opção de que trata o inciso III do $\S 4^{\circ}$ do art. 153 da Constituição, pelos Municípios e pelo Distrito Federal, para fins de fiscalização e cobrança do Imposto sobre a Propriedade Territorial Rural - ITR, e dá outras providências. Diário Oficial da União, Brasília, DF, 15 abr. 2008. 
BRASIL. Emenda Constitucional n. 42, de 19 de dezembro de 2003. Código Tributário Nacional. Altera o Sistema Tributário Nacional e dá outras providências. Diário Oficial da União, Brasília, DF, 19 dez. 2003.

BRASIL. Lei n. 9.393, de 19 de dezembro de 1996. Dispõe sobre o Imposto sobre a Propriedade Territorial Rural - ITR, sobre pagamento da dívida representada por Títulos da Dívida Agrária e dá outras providências. Diário Oficial da União, Brasília, DF, 19 dez. 1996.

BRASIL. Lei n. 11.250, de 27 de dezembro de 2005. Regulamenta o inciso III do $\S 4^{\circ}$ do art. 153 da Constituição Federal. Diário Oficial da União, Brasília, DF, 27 dez. 2005.

BUSSAB, W. O.; MORETTIN, P. A. Estatística Básica. 4. ed. São Paulo: Atual, 1987.

CRUZ, F.; LUZ, M. B.; UHLMANN, V. O. Análise sobre o comportamento das adesões pelos municípios do Estado do Rio Grande do Sul ao convênio do Imposto sobre a propriedade territorial rural. Revista RACE, v. 11, n. 2, p. 295-318, jul./dez. 2012.

HAIR JÚNIOR, F. et al. Fundamentos e métodos de pesquisa em administração. Tradução Lene Belon Ribeiro. Porto Alegre: Bookman, 2005.

INTERNATIONAL MONETARY FUND. Brazil: issues for fundamental tax reform. Washington: Fiscal Affairs Department/IMF, 1992.

MACHADO, H. B. Curso de direito tributário. 31. ed. São Paulo: Malheiros Editores, 2010.

OLIVEIRA, T. A. M. Imposto Territorial Rural: um estudo econômico sobre a descentralização da cobrança. 2010. Dissertação (Mestrado em Economia)-Universidade Estadual de Campinas, Campinas, 2010.

RODRIGUES, F. C. O Imposto Territorial Rural (ITR) como fonte de receita municipal. 2012. Dissertação (Pós-graduação em Economia e Mestrado profissional em Economia)-Universidade Federal do Ceará, Fortaleza, 2012. 
SOUZA, E. G. ITR: uma legislação eficiente e uma arrecadação incongruente. Secretaria da Receita Federal. $3^{\circ}$ Prêmio Schöntag. 2004. Disponível em: <http://www. receita.fazenda.gov.br/Publico/premios/schontag/2004/Terceirolugar.pdf > . Acesso em: 25 mar. 2015.

SOUZA, E. G.; JORGE, W. J. O imposto territorial rural no Brasil: uma análise da experiência de municipalização - 1961-1964. Jaboticabal: FCAV/FUNDUNESP, 1999.

WILLIAMSON, I. Using cadastres to support sustainable development. International Federation of Surveyors, Apr. 2008.

\section{Como citar este artigo:}

\section{ABNT}

MASSARDI, Wellington de Oliveira et al. Descentralização do imposto territorial rural: um estudo aplicado aos municípios de minas gerais. RACE, Revista de Administração, Contabilidade e Economia, Joaçaba: Ed. Unoesc, v. 15, n. 3, p. 871891, set./dez. 2016. Disponível em: <http://editora.unoesc.edu.br/index.php/race>. Acesso em: dia/mês/ano.

\section{APA}

Massardi, W. de O., Araújo, P.S., Ciribeli, J. P., \& Silva, E. T. da. (2016). Descentralização do imposto territorial rural: um estudo aplicado aos municípios de minas gerais. RACE, Revista de Administração, Contabilidade e Economia, 15(3), 871891. Recuperado em dia/mês/ano, de http://editora.unoesc.edu.br/index.php/race 
